\title{
SAXS: Aspectos básicos e algumas aplicações em ciência e engenharia de materiais.
}

\begin{abstract}
$\frac{\text { Aldo Craievich }}{U S P}$
A apresentação será iniciada com uma introdução básica ao método de espalhamento de raios X a baixos ângulos (SAXS). Serão depois descritas algumas aplicações de interesse para a ciência e tecnologia de materiais, tais como (i) estudos da formação de zonas de Guinier-Preston ("GP zones") em ligas metálicas, (ii) análises da influencia da separação de fases vítreas nos processos de cristalização controlada de vitrocerâmicos, (iii) caracterizações in situ de processos de preparação tipo "bottom-up" e transformações de fase de materiais nanoestruturados compostos de matriz vítrea contendo "quantumdots" metálicos e semicondutores.
\end{abstract}

